\title{
Podsumowanie wskazań do implantacji układów stymulujących serce
}

\section{Summary of indications for implanting a cardiac stimulating systems}

\author{
Roman Załuska1, Marcin Bobruk2, 3 , Marcin Grabowski \\ ${ }^{1}$ Oddział Kardiologiczny Mazowieckiego Szpitala Specjalistycznego im. dr. Józefa Psarskiego w Ostrołęce \\ ${ }^{2}$ Wydział Nauk o Zdrowiu Uniwersytetu Medycznego w Łodzi \\ ${ }^{3}$ Rada Ekspertów Uczelni Łazarskiego \\ ${ }^{4}$ I Katedra i Klinika Kardiologii Warszawskiego Uniwersytetu Medycznego
}

\section{STRESZCZENIE}

Nieprzerwany rozwój gamy dostępnych urządzeń do stałej stymulacji serca wymaga coraz precyzyjniejszej diagnostyki na etapie doboru właściwej metody stymulacji zależnie od schorzenia, objawów, skuteczności i ryzyka powikłań. Autorzy dokonują przeglądu obecnego stanu literatury oraz zalecań dla szczególnych grup pacjentów. W kontekście przedstawionych wyników i własnych doświadczeń autorzy wskazują mikrostymulatory jako urządzenia, które mogą być przyszłością stałej stymulacji serca.

Choroby Serca i Naczyń 2019, 16 (4), 248-256 Słowa kluczowe: stymulacja mięśnia sercowego, bradyarytmia, bradykardia, omdlenia, mechanizm kardiodepresyjny

\section{ABSTRACT}

The continuous development of a range of devices for permanent cardiac pacing requires increasingly precise diagnostics at the stage of selection of the correct stimulation method, depending on the disease, symptoms, efficacy and risk of complications. The authors review the current state of the literature as well as making recommendations for specific patient groups. In the context of the results presented and their own experience, the authors suggest microstimulators to be devices that may represent the future of permanent cardiac pacing.

$$
\text { Choroby Serca i Naczyń 2019, } 16 \text { (4), 248-256 }
$$

Key words: myocardial stimulation, bradyarrhythmia, bradycardia, syncope, cardio depression

\section{WPROWADZENIE}

Stała stymulacja serca ma ugruntowaną pozycję w terapii zaburzeń bodźcotwórczości oraz przewodnictwa przedsionkowo-komorowego. Od wprowadzenia przed laty do tej pory obserwuje się stały postęp w zakresie rozwiązań technicznych układów stymulujących polegający na ich miniaturyzacji, możliwości

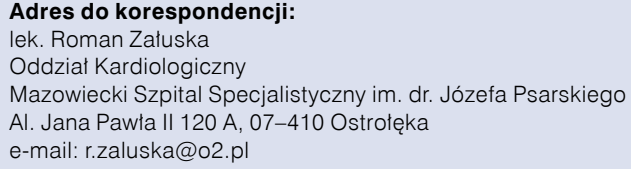

programowania oraz uzyskiwania informacji o rytmie pacjenta.

Podstawowym wskazaniem do wszczepienia układu stymulującego serce jest spowodowana różnymi mechanizmami bradykardia występująca stale lub napadowa. Pacjenci zgłaszają się po pomoc z różnie nasilonymi, często niecharakterystycznymi dolegliwościami. Począwszy od nawracających, często urazowych utrat przytomności, poprzez zawroty głowy, stany przedomdleniowe, omdlenia, pogorszenie tolerancji wysiłku fizycznego do zaburzeń koncentracji, apatii, znużenia, drażliwości oraz zmian charakterologicznych zwykle uważanych za typowe dla wieku starszego. Czasem zgłaszane dolegliwości są interpretowane jako napady padaczkowe lub epizody przemijającego niedokrwienia 
mózgu (TIA, transient ischaemick attack) i niepotrzebnie, nieskutecznie zresztą, leczone neurologicznie. Dotyczy to napadowych, rzadko występujących bradyarytmii. W przypadkach zarejestrowania wolnej czynności serca należy wdrożyć badania diagnostyczne w celu wyjaśnienia mechanizmu bradykardii, ale także ustalenia ewentualnej odwracalnej przyczyny. W każdym przypadku należy przeanalizować stosowaną terapię, zidentyfikować zaburzenia elektrolitowe, wykluczyć zatrucia. Leczenie przyczynowe pozwala poprawić stan chorego i zapobiec niepotrzebnemu zabiegowi. Po wykluczeniu odwracalnych przyczyn wolnej czynności serca należy przeanalizować wskazania do implantacji układu stymulującego. Wskazania te opierają się na ustaleniu mechanizmu bradykardii, określeniu jej nasilenia oraz symptomatologii klinicznej. Najczęstszymi przyczynami utrwalonej bradyarytmii są choroba węzła zatokowego oraz zaburzenia przewodnictwa przedsionkowo-komorowego.

\section{Wstępna diagnostyka zasłabnięć - kryteria}

Niezwykle ważne jest wykazanie, za pomocą właściwie dobranych narzędzi diagnostycznych, korelacji między zgłaszanymi dolegliwościami a zarejestrowaną bradykardią. W przypadku dolegliwości występujących w chwili badania pacjenta może wystarczyć standardowe badanie elektrokardiograficzne (EKG), a badanie EKG metodą Holtera z czasem rejestracji od 24 godzin do tygodnia, jeśli objawy występują 2-3 razy w tygodniu. W przypadku zasłabnięć występujących kilka razy w miesiącu wartościową techniką może się okazać zewnętrzny wszczepialny rejestrator pętlowy (ILR, implantable loop recorder), za pomocą którego można prowadzić rejestrację nawet przez kilka lat.

W tabeli 1 podano zmiany w zapisie EKG sugerujące kardiogenną etiologię zasłabnięcia [1].

\section{WYNIKI}

Liczba wyników wartościowych pod względem diagnostycznym wynosi około $24,5 \%$, przy czym najczęściej występują epizody bradykardii [17-19]. Jeśli dolegliwości występują rzadko, to należy rozważyć wszczepienie ILR. Urządzenie te pozwala nawet kilkakrotnie zwiększyć prawdopodobieństwo rozpoznania przyczyny omdlenia. Obiecujące wyniki uzyskano w przypadku pacjentów z blokiem odnóg pęczka Hisa $\mathrm{z}$ ujemnym wynikiem badania elektrofizjologicznego (EPS, electrophysiological study). Za pomocą ILR udało się wykryć arytmię u około $40 \%$ chorych. Napadowy blok przedsionkowo-komorowy wystąpił u około $70 \%$ [20-22]. Interesujące wyniki uzyskano także u pacjentów z nieskutecznie leczoną padaczką. Okazało się, że w $26 \%$ przypadków napady drgawkowe były spowodowane zaburzeniami rytmu serca [23-26]. Diagnostyka za pomocą ILR okazała się także tańsza niż standardowe postępowanie [27-30]. Niestety ta technika nie jest aktualnie w Polsce refundowana przez płatnika publicznego. W ostatnich latach pojawiły się również kolejne, nowe możliwości diagnostyczne. Opracowano i wdrożono zewnętrzne oraz wszczepialne rejestratory transmitujące zapis EKG do ośrodka monitorującego w czasie rzeczywistym [31-33].

W diagnostyce zasłabnięć, których symptomatologia sugeruje mechanizm odruchowy, należy wykonać masaż zatoki tętnicy szyjnej, przydatny może być test pochyleniowy, a badanie wysiłkowe - jeśli dolegliwości występują w czasie aktywności fizycznej lub wkrótce po niej. Jeżeli blok przedsionkowo-komorowy II-III stopnia wystąpi podczas wysiłku, to nawet jeśli nie doszło do omdlenia, jest to niepodważalny dowód patologii przewodnictwa przedsionkowo-komorowego [34-38]. Wykazano, że blok tego typu jest blokiem dystalnym $\mathrm{w}$ stosunku do węzła przedsionkowo-



ICD (implantable cardioverter-defibrillator) — implantowalny kardiowerter-defibrylator 
Tabela 2. Wskazania do badania elektrofizjologicznego (EPS, electrophysiological study) (źródło [1])

Wskazanie

Pacjent $z$ omdleniem po przebytym zawale serca lub z innym schorzeniem powodującym powstanie blizny w mięśniu sercowym

EPS jest wskazane, jeśli badania nieinwazyjne nie przynoszą wyjaśnienia przyczyny [43]

Pacjent z omdleniem i blokiem dwuwiązkowym

EPS do rozważenia, jeżeli omdlenie pozostaje niewyjaśnione [44-49]

Pacjent z omdleniem i bezobjawową bradykardią zatokową

EPS w pewnych sytuacjach może być wskazane w przypadku braku korelacji między omdleniem a bradykardią [50-52]

Pacjent z omdleniem poprzedzonym nagłym kołataniem serca

Nie udało się wyjaśnić przyczyny metodami diagnostyki nieinwazyjnej
Klasa zalecen

I

$\mathrm{B}$

IIa

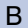

IIb

B

IIb

C -komorowego [34] i należy się spodziewać progresji do bloku stałego [35, 36]. Pozwala to na kwalifikacje pacjenta do leczenia za pomocą stymulatora. $W$ uzasadnionych przypadkach należy wykonać EPS (omdlenia u pacjentów z blokiem odnogi pęczka Hisa, bezobjawowa bradykardia zatokowa - podejrzenie zahamowania zatokowego, blok dwuwiązkowy — zagrażający blok przedsionkowo-komorowy wysokiego stopnia [39], nieudokumentowane napadowe kołatania serca). Uważa się, że dodatni wynik EPS wskazuje na napadowy blok przedsionkowo-komorowy jako przyczynę omdlenia [40, 41]. Należy jednak zdawać sobie sprawę z faktu, że zastosowane techniki mogą dawać wyniki fałszywie ujemne oraz fałszywie dodatnie, co ogranicza ich wartość diagnostyczną. Podstawową wartość diagnostyczną mają rejestracja rytmu serca oraz odpowiedź układu sercowo-naczyniowego na zaistniałe zdarzenie [42]. Rzadko jednak ma się do czynienia z taką sytuacją. Przedłużone monitorowanie rytmu serca odpowiednio dobraną techniką ma dużą wartość diagnostyczną, ale może znacząco opóźnić właściwe rozpoznanie oraz wdrożenie leczenia. Naraża to pacjentów na powtarzające się urazy, a nawet śmierć.

Wskazania do EPS podano w tabeli 2 [1], a w tabeli 3 [1] zawarto informacje dotyczące leczenia w zależności od wyniku tego badania.

\section{Choroba węzla zatokowego}

Objawowa bradykardia zatokowa jest podstawowym wskazaniem do zastosowania stałej stymulacji, przy czym celem tego leczenia jest poprawienie jakości życia chorych. Nie uzyskano dotychczas dowodów poprawy rokowania $w$ tej populacji. Podstawową trudnością w kwalifikowaniu tych chorych jest trudność jednoznacznego wykazania, że zgłaszane dolegliwości wynikają jedynie z wolnej czynności serca. Problem ten bardzo często dotyczy osób w podeszłym wieku z wieloma chorobami współistniejącymi, których symptomatologia może być podobna. Drugą ważną grupą są osoby młode uprawiające sporty wytrzymałościowe. Powszechnym zjawiskiem u tych pacjentów pozostaje bradykardia zatokowa wynikająca z przewagi regulacji przywspółczulnej. Obserwuje się zwolnienie czynności serca do 30/min w czasie snu i jest to zjawisko fizjologiczne.

\section{Zaburzenia przewodnictwa przedsionkowo-komorowego}

W przypadku zaburzeń przewodnictwa przedsionkowo-komorowego dostępnych jest znacznie więcej dowodów naukowych pozwalających podjąć właściwą decyzję terapeutyczną (patrz tab. 4 [55]). Poprawę rokowania udowodniono nawet $\mathrm{u}$ często pozornie niewykazujących objawów pacjentów z blokiem III stopnia oraz blokiem przedsionkowo-komorowym II stopnia typu 2. W przypadku bloku drugiego stopnia typu 1 o implantacji układu stymulującego decyduje się na podstawie symptomatologii.

\section{Udokumentowana przejściowa bradyarytmia}

W chorobie węzła zatokowego można wyróżnić dwie postacie napadowej bradykardii, które w przypadku udowodnienia korelacji między objawami a zwolnieniem czynności serca stanowią wskazanie do implantacji stymulatora w celu poprawy jakości życia:

1) napadowe zahamowanie zatokowe lub blok zatokowo-przedsionkowy u pacjentów $\mathrm{z}$ łagodną postacią choroby węzła zatokowego (częstość rytmu podstawowego 40-50/min);

2) przedłużona, zwykle powyżej 3 sekund, pauza rytmu zatokowego w następstwie zahamowania zatokowe- 
Tabela 3. Leczenie zależne od wyniku badania elektrofizjologicznego (EPS, electrophysiological study) (źródiło [1])

Wskazanie

Pacjent z niewyjaśnionym omdleniem i blokiem dwuwiązkowym

Wszczepienie stymulatora jest wskazane w przypadku odstępu H-V w warunkach spoczynkowych z 70 ms bądź wystąpienia bloku II lub III stopnia w obrębie układu Hisa-Purkinjego podczas stymulacji przedsionków ze stopniowo zwiększaną częstością albo podczas próby farmakologicznej [44-49]

Pacjent $z$ omdleniem po przebytym zawale serca lub z innym schorzeniem powodującym powstanie blizny w mięśniu sercowym

W przypadku wywołania utrwalonego, jednokształtnego częstoskurczu komorowego postępowanie musi być zgodnie z aktualnymi wytycznymi dotyczącymi komorowych zaburzeń rytmu serca [53]

Pacjent bez strukturalnej choroby serca $z$ omdleniem poprzedzonym napadowym kołataniem serca

W przypadku wywołania tachyarytmii nadkomorowej z szybką czynnością komór lub częstoskurczu komorowego przebiegających z objawową hipotonią lub symptomatologią zbliżoną do występującej podczas zasłabnięcia spontanicznego postępowanie powinno być zgodne $z$ aktualnymi wytycznymi $[53,54]$

Pacjent z omdleniem i bezobjawową bradykardią zatokową

Klasa zaleceń Poziom wiarygodności danych

B

Wszczepienie stymulatora należy rozważyć, jeżeli w EPS stwierdza się wydłużenie skorygowanego SNRT [50-52]

SNRT (sinus nodal reentrant tachycardia) — nawrotny częstoskurcz zatokowy

Tabela 4. Wskazania do implantacji układu stymulującego w chorobie węła zatokowego oraz zaburzeniach przewodnictwa przedsionkowo-komorowego (AV, atrioventricular) (źródło [55])

Zalecenie

Klasa zaleceń Poziom wiarygodności danych

\section{Choroba węzła zatokowego}

Wszczepienie stymulatora jest wskazane, jeśli wykazano korelację między dolegliwościami a bradykardią [56-60]

Stymulację serca można rozważyć, jeśli objawy są prawdopodobnie wynikiem bradykardii, nawet jeśli dowody pozostają niejednoznaczne

Stymulacja serca jest przeciwwskazana u pacjentów z bezobjawową bradykardią zatokową lub w przypadku potencjalnie odwracalnej bradykardii zatokowej

\section{Nabyty blok AV}

Blok AV III stopnia oraz blok AV II stopnia typu 2

Stymulacja serca jest wskazana niezależnie od objawów

Blok AV II stopnia typu 1 objawowy lub zlokalizowany na poziomie lub poniżej pęczka Hisa (w EPS)

Należy rozważyć stymulację serca

Blok AV spowodowany przyczynami odwracalnymi

Stymulacja serca jest przeciwwskazana

EPS (electrophysiological study) - badanie elektrofizjologiczne

go po zakończeniu tachyarytmii w zespole bradykardia-tachykardia [56-58].

Nawet u połowy pacjentów z chorobą węzła zatokowego obserwuje się zasłabnięcia odruchowe (dodatni test pochyleniowy - mechanizm kardiodepresyjny, nadwrażliwość zatoki tętnicy szyjnej). W związku z tym u około $1 / 5$ pacjentów po wszczepieniu stymulatora na podstawie tych wskazań obserwuje się, niestety, nawroty omdleń.
W badaniach obserwacyjnych dotyczących zespołu nadwrażliwej zatoki tętnicy szyjnej wykazano, że stała stymulacja serca zmniejszyła nasilenie zgłaszanych dolegliwości nawet o 80-90\% [59-62]. Jednak w trwającej 3 lata obserwacji stwierdzono nawroty zasłabnięć u około $1 / 4$ chorych. W przypadku kardiodepresyjnej postaci omdleń odruchowych (wykazanej w teście pochyleniowym) zalecenia również nie są pewne. W przypadkach, w których implantowano stymulator, zgłaszane 
wcześniej objawy często nadal występują [61, 62]. Jeżeli nie wykazano mechanizmu kardiodepresyjnego, to przydatne może być zastosowanie ILR w ramach próby udokumentowania mechanizmu omdlenia.

Rzadko występującą postacią przemijającego bloku przedsionkowo-komorowego jest idiopatyczny blok przedsionkowo-komorowy $[63,64]$. Występuje on zwykle u pacjentów z długim wywiadem zasłabnięć, u których — poza bardzo niskim stężeniem adenozyny — nie stwierdza sięinnych nieprawidłowości. Skuteczność stymulacji wykazano w nielicznych, małych badaniach [65].

Wskazania do wszczepienia stymulatora w przypadku omdleń odruchowych podano w tabeli 5 [1].

\section{Szczególne grupy pacjentów (patrz także tab. 6) Ostry zawał serca}

W dobie interwencyjnego leczenia ostrego zawału serca blok przedsionkowo-komorowy występuje rza-

Tabela 5. Wskazania do wszczepienia stymulatora w przypadku omdleń odruchowych (źródło [1])

\begin{tabular}{|c|c|c|}
\hline Wskazania & Klasa zaleceń & $\begin{array}{l}\text { Poziom wiarygodności } \\
\text { danych }\end{array}$ \\
\hline $\begin{array}{l}\text { Pacjent w wieku powyżej } 40 \text { lat, z nawracającymi omdleniami oraz udokumento- } \\
\text { waną, spontanicznie występującą asystolią trwającą }>3 \mathrm{~s} \mathrm{lub} \text { asystolią bezobja- } \\
\text { wową trwającą }>6 \mathrm{~s} \text { w mechanizmie zahamowania zatokowego, bloku przedsion- } \\
\text { kowo-komorowego lub kombinacją tych zaburzeń }\end{array}$ & Ila & B \\
\hline \multicolumn{3}{|l|}{$\begin{array}{l}\text { Implantacja stymulatora celem zmniejszenia częstości występowania omdleń [59- } \\
\text {-61,67] }\end{array}$} \\
\hline $\begin{array}{l}\text { Pacjent w wieku > } 40 \text { lat z często nawracającymi omdleniami w przebiegu kardio- } \\
\text { depresyjnej postaci zespołu zatoki szyjnej }\end{array}$ & Ila & B \\
\hline \multicolumn{3}{|l|}{ Implantacja stymulatora celem zmniejszenia częstości nawrotów omdleń $[60,62,68]$} \\
\hline $\begin{array}{l}\text { Pacjent w wieku powyżej } 40 \text { lat z częstymi, nieprzewidywalnymi nawrotami } \\
\text { omdleń, u którego wywołano asystolię w teście pochyleniowym }\end{array}$ & $\mathrm{Ilb}$ & B \\
\hline \multicolumn{3}{|l|}{$\begin{array}{l}\text { Implantacja stymulatora może być rozważana celem zmniejszenia częstości nawrotów } \\
{[60,69-71]}\end{array}$} \\
\hline Pacjent z omdleniem zależnym od adenozyny & $1 \mathrm{llb}$ & B \\
\hline \multicolumn{3}{|l|}{$\begin{array}{l}\text { Implantacja stymulatora może być rozważana celem zmniejszenia częstości nawrotów } \\
\text { omdleń jeżeli występują kliniczne cechy omdlenia zależnego od adenozyny }[65,72,73]\end{array}$} \\
\hline $\begin{array}{l}\text { Pacjent, u którego nie udokumentowano kardiodepresyjnego mechanizmu } \\
\text { omdlenia }\end{array}$ & III & B \\
\hline Stymulacja jest przeciwskazana $[73,74]$ & & \\
\hline
\end{tabular}

Tabela 6. Wskazania do stymulacji po operacji serca, przezcewnikowej implantacji zastawki aortalnej (TAVI, transcatheter aortic valve implantation) i transplantacji serca (źródło [55])

Zalecenie

Pacjent z blokiem całkowitym lub blokiem AV wysokiego stopnia po operacji kardiochirurgicznej lub TAVI:

- w przypadku bloku AV wysokiego stopnia zaleca się maksymalnie 7-dniowy okres obserwacji

- w przypadku bloku całkowitego z wolną częstością rytmu zastępczego uzasadnione jest skrócenie okresu obserwacji, ponieważ ustąpienie bloku jest mało prawdopodobne

Implantacja stymulatora jest wskazana, jeśli bradyarytmia nie ustąpi

Pacjent z zaburzeniami czynności węzła zatokowego po zabiegach kardiochirurgicznych lub transplantacji serca

Zalecany okres obserwacji wynosi od 5 dni do kliku tygodni

Implantacja stymulatora jest wskazana, jeśli bradyarytmia nie ustąpi

Pacjent po transplantacji serca z objawową niewydolnością chronotropową

Należy rozważyć implantację stymulatora w przypadku pogorszenia jakości życia spowodowanej niewydolnością chronotropową w późnym okresie po transplantacji
Klasa zaleceń Poziom wiarygodności danych

C

C

Ila

C

AV (atrioventricular) - przedsionkowo-komorowy 
dziej i zwykle ustępuje samoistnie w ciągu kilku dni do kilku tygodni [76-79]. Około 1/10 pacjentów wymaga jednak stałej stymulacji [80].

\section{Pacjent po operacji kardiochirurgicznej, przezcewnikowej implantacji zastawki aortalnej}

Po zabiegach kardiochirurgicznych dość często występują przemijające bradyarytmie. Nie udało się jednak jednoznacznie ustalić, jaki jest optymalny czas oczekiwania na samoistny powrót prawidłowej bodźcotwórczości i przewodnictwa przedsionkowo-komorowego. W związku z tym przyjęto arbitralnie okres 7 dni w przypadku bloku przedsionkowo-komorowego wysokiego stopnia, natomiast w przypadku zaburzeń funkcji węzła zatokowego zalecono obserwację kilutygodniową.

\section{Pacjent po transplantacji serca}

U pacjentów po transplantacji serca zwykle obserwuje się niewydolność chronotropową przeszczepionego narządu. Wynika to z utraty kontroli autonomicznego układu nerwowego. Spontaniczna poprawa występuje zazwyczaj w ciągu pierwszych 3 tygodni po operacji. Jednak w około $8 \%$ przypadków objawowa bradykardia utrzymuje się i należy implantować układ stymulujący serca w celu poprawienia jakości życia tych chorych.

\section{Kardiomiopatia przerostowa}

W przypadku kardiomiopatii przerostowej z zawężeniem drogi odpływu lewej komory z towarzyszącymi objawami, nieskutecznej farmakoterapii oraz przeciwskazań do ablacji alkoholowej przegrody lub miektomii można rozważyć implantację układu stymulującego (klasa zalecenia IIb). Układ ten powinien być odpowiednio zaprogramowany [81-87].

\section{PODSUMOWANIE}

Wszczepianie klasycznych układów wiąże się z ryzykiem wystąpienia wielu powikłań — zarówno infekcyjnych, jak i związanych z uszkodzeniem elektrod. Starsze urządzenia uniemożliwiały również wykonywanie, czasem niezbędnej, diagnostyki z wykorzystaniem rezonansu magnetycznego (MRI, magnetic resonance imaging). Najnowszym, wdrażanym obecnie, systemem jest miniaturowy układ bezelektrodowy Micra. Stymulator tego typu jest implantowany przede wszystkim pacjentom z występującymi wcześniej powikłaniami klasycznej stymulacji. Wskazania są obecnie ograniczone do przypadków wolnej częstości rytmu serca w obrębie migotania przedsionków, ale pod uwagę są również brani pacjenci z rytmem zatokowym i rzadko występującymi bradyarytmiami. Technika ta jest stale udoskonalana i w przyszłości należy się spodziewać możliwości wszczepiania mikrostymulatorów także do przedsionka serca, co istotnie poszerzy zakres wskazań do tego nowoczesnego leczenia. Zabieg jest małoinwazyjny, a ponadto możliwa jest diagnostyka MRI u tych pacjentów. Wydaje się, że jest to techniczna przyszłość elektroterapii. Mniejszą dynamikę można zaobserwować w ewolucji wskazań do leczenia z użyciem układów stymulujących serce.

\section{PIŚMIENNICTWO}

1. Brignole M, Moya A, de Lange FJ, et al. Grupa Robocza Europejskiego Towarzystwa Kardiologicznego (ESC) ds. rozpoznawania i leczenia omdleń. Wytyczne ESC dotyczące rozpoznawania i leczenia omdleń (2018). Kardiol Pol. 2018; 76(8): 1119-1198, doi: 10.5603/ /KP.2018.0161, indexed in Pubmed: 30117520

2. Sarasin FP, Hanusa BH, Perneger T, et al. A risk score to predict arrhythmias in patients with unexplained syncope. Acad Emerg Med. 2003; 10(12): 1312-1317, doi: 10.1111/j.1553-2712.2003.tb00003.x, indexed in Pubmed: 14644781.

3. Quinn J, McDermott D, Stiell I, et al. Prospective validation of the San Francisco Syncope Rule to predict patients with serious outcomes. Ann Emerg Med. 2006; 47(5): 448-454, doi: 10.1016/j.annemergmed.2005.11.019, indexed in Pubmed: 16631985.

4. Middlekauff HR, Stevenson WG, Stevenson LW, et al. Syncope in advanced heart failure: high risk of sudden death regardless of origin of syncope. J Am Coll Cardiol. 1993; 21(1): 110-116, doi: 10.1016/07351097(93)90724-f, indexed in Pubmed: 8417050.

5. Brembilla-Perrot B, Suty-Selton C, Beurrier D, et al. Differences in mechanisms and outcomes of syncope in patients with coronary disease or idiopathic left ventricular dysfunction as assessed by electrophysiologic testing. J Am Coll Cardiol. 2004; 44(3): 594-601, doi: 10.1016/j. jacc.2004.03.075, indexed in Pubmed: 15358027.

6. Steinberg JS, Beckman K, Greene HL, et al. Follow-up of patients with unexplained syncope and inducible ventricular tachyarrhythmias: analysis of the AVID registry and an AVID substudy. Antiarrhythmics Versus Implantable Defibrillators. J Cardiovasc Electrophysiol. 2001; 12(9): 996-1001, doi: 10.1046/j.1540-8167.2001.00996.x, indexed in Pubmed: 11573709

7. Pezawas T, Stix G, Kastner J, et al. Unexplained syncope in patients with structural heart disease and no documented ventricular arrhythmias: value of electrophysiologically guided implantable cardioverter defibrillator therapy. Europace. 2003; 5(3): 305-312, doi: 10.1016/ /s1099-5129(03)00044-8, indexed in Pubmed: 12842649.

8. Olshansky B, Poole JE, Johnson G, et al. SCD-HeFT Investigators. Syncope predicts the outcome of cardiomyopathy patients: analysis of the SCD-HeFT study. J Am Coll Cardiol. 2008; 51(13): 1277-1282, doi: 10.1016/j.jacc.2007.11.065, indexed in Pubmed: 18371559.

9. Goldberger JJ, Cain ME, Hohnloser SH, et al. American Heart Association, American College of Cardiology Foundation, Heart Rhythm Society. American Heart Association/American College of Cardiology Foundation/Heart Rhythm Society Scientific Statement on Noninvasive Risk Stratification Techniques for Identifying Patients at Risk for Sudden Cardiac Death. A scientific statement from the American Heart Association Council on Clinical Cardiology Committee on Electrocardiography and Arrhythmias and Council on Epidemiology and Prevention. J Am Coll Cardiol. 2008; 52(14): 1179-1199, doi: 10.1016/j. jacc.2008.05.003, indexed in Pubmed: 18804749. 
10. Del Rosso A, Alboni P, Brignole M, et al. Relation of clinical presentation of syncope to the age of patients. Am J Cardiol. 2005; 96(10) 1431-1435, doi: 10.1016/j.amjcard.2005.07.047, indexed in Pubmed: 16275193

11. Martin TP, Hanusa BH, Kapoor WN. Risk stratification of patients with syncope. Ann Emerg Med. 1997; 29(4): 459-466, doi: 10.1016/s01960644(97)70217-8, indexed in Pubmed: 9095005.

12. Colivicchi F, Ammirati F, Melina D, et al. OESIL (Osservatorio Epidemiologico sulla Sincope nel Lazio) Study Investigators. Development and prospective validation of a risk stratification system for patients with syncope in the emergency department: the OESIL risk score. Eur Heart J. 2003; 24(9) : 811-819, doi: 10.1016/s0195-668x(02)00827-8, indexed in Pubmed: 12727148

13. Del Rosso A, Ungar A, Maggi R, et al. Clinical predictors of cardiac syncope at initial evaluation in patients referred urgently to a general hospital: the EGSYS score. Heart. 2008; 94(12): 1620-1626, doi: 10.1136/hrt.2008.143123, indexed in Pubmed: 18519550

14. Mittal S, Hao SC, Iwai S, et al. Significance of inducible ventricular fibrillation in patients with coronary artery disease and unexplained syncope. J Am Coll Cardiol. 2001; 38(2): 371-376, doi: 10.1016/ /s0735-1097(01)01379-1, indexed in Pubmed: 11499726.

15. Del Rosso A, Alboni P, Brignole M, et al. Diagnostic value of history in patients with syncope with or without heart disease. J Am Coll Cardiol. 2001; 37(7): 1921-1928, doi: 10.1016/s0735-1097(01)01241-4, indexed in Pubmed: 11401133

16. Berecki-Gisolf $\mathrm{J}$, Sheldon A, Wieling W, et al. Identifying cardiac syncope based on clinical history: a literature-based model tested in four independent datasets. PLoS One. 2013; 8(9): e75255, doi: 10.1371/ /journal.pone.0075255, indexed in Pubmed: 24223233

17. Locati ET, Moya A, Oliveira M, et al. External prolonged electrocardiogram monitoring in unexplained syncope and palpitations: results of the SYNARR-Flash study. Europace. 2016; 18(8): 1265-1272, doi: 10.1093/europace/euv311, indexed in Pubmed: 26519025

18. Linzer M, Pritchett EL, Pontinen M, et al. Incremental diagnostic yield of loop electrocardiographic recorders in unexplained syncope. Am J Cardiol. 1990; 66(2): 214-219, doi: 10.1016/0002-9149(90)90591-n, indexed in Pubmed: 2371954.

19. Schuchert A, Maas R, Kretzschmar C, et al. Diagnostic yield of external electrocardiographic loop recorders in patients with recurrent syncope and negative tilt table test. Pacing Clin Electrophysiol. 2003; 26(9): 1837-1840, doi: 10.1046/j.1460-9592.2003.t01-1-00277.x, indexed in Pubmed: 12930497.

20. Da Costa A, Defaye P, Romeyer-Bouchard C, et al. Clinical impact of the implantable loop recorder in patients with isolated syncope, bundle branch block and negative workup: a randomized multicentre prospective study. Arch Cardiovasc Dis. 2013; 106(3): 146-154, doi: 10.1016/j.acvd.2012.12.002, indexed in Pubmed: 23582676.

21. Brignole M, Menozzi C, Moya A, et al. International Study on Syncope of Uncertain Etiology (ISSUE) Investigators. Mechanism of syncope in patients with bundle branch block and negative electrophysiological test. Circulation. 2001; 104(17): 2045-2050, doi: 10.1161/ /hc4201.097837, indexed in Pubmed: 11673344.

22. Moya A, García-Civera R, Croci F, et al. Bradycardia detection in Bundle Branch Block (B4) study. Diagnosis, management, and outcomes of patients with syncope and bundle branch block. Eur Heart J. 2011; 32(12): 1535-1541, doi: 10.1093/eurheartj/ehr071, indexed in Pubmed: 21444367.

23. Zaidi A, Clough P, Cooper P, et al. Misdiagnosis of epilepsy: many seizure-like attacks have a cardiovascular cause. J Am Coll Cardiol. 2000; 36(1): 181-184, doi: 10.1016/s0735-1097(00)00700-2, indexed in Pubmed: 10898432.

24. Ho RT, Wicks T, Wyeth D, et al. Generalized tonic-clonic seizures detected by implantable loop recorder devices: diagnosing more than cardiac arrhythmias. Heart Rhythm. 2006; 3(7): 857-861, doi: 10.1016/j. hrthm.2006.03.026, indexed in Pubmed: 16818222
25. Petkar S, Hamid T, Iddon P, et al. Prolonged implantable electrocardiographic monitoring indicates a high rate of misdiagnosis of epilepsy —REVISE study. Europace. 2012; 14(11): 1653-1660, doi: 10.1093/ /europace/eus185, indexed in Pubmed: 22753867

26. Maggi R, Rafanelli M, Ceccofiglio A, et al. Additional diagnostic value of implantable loop recorder in patients with initial diagnosis of real or apparent transient loss of consciousness of uncertain origin. Europace. 2014; 16(8): 1226-1230, doi: 10.1093/europace/euu051, indexed in Pubmed: 24668513.

27. Farwell DJ, Freemantle N, Sulke N, et al. Use of implantable loop recorders in the diagnosis and management of syncope. Eur Heart J. 2004; 25(14): 1257-1263, doi: 10.1016/j.ehj.2004.03.010, indexed in Pubmed: 15246645.

28. Krahn AD, Klein GJ, Yee R, et al. Randomized assessment of syncope trial: conventional diagnostic testing versus a prolonged monitoring strategy. Circulation. 2001; 104(1): 46-51, doi: 10.1161/01. cir.104.1.46, indexed in Pubmed: 11435336.

29. Edvardsson N, Garutti C, Rieger G, et al. PICTURE Study Investigators. Unexplained syncope: implications of age and gender on patient characteristics and evaluation, the diagnostic yield of an implantable loop recorder, and the subsequent treatment. Clin Cardiol. 2014; 37(10): 618-625, doi: 10.1002/clc.22300, indexed in Pubmed: 24890550.

30. Edvardsson N, Wolff C, Tsintzos S, et al. Costs of unstructured investigation of unexplained syncope: insights from a micro-costing analysis of the observational PICTURE registry. Europace. 2015; 17(7): 1141-1148, doi: 10.1093/europace/euu412, indexed in Pubmed: 25759408.

31. Drak-Hernández Y, Toquero-Ramos J, Fernández JM, et al. Effectiveness and safety of remote monitoring of patients with an implantable loop recorder. Rev Esp Cardiol (Engl Ed). 2013; 66(12): 943-948, doi: 10.1016/j.rec.2013.06.009, indexed in Pubmed: 24774107.

32. Furukawa T, Maggi R, Bertolone $\mathrm{C}$, et al. Effectiveness of remote monitoring in the management of syncope and palpitations. Europace. 2011; 13(3): 431-437, doi: 10.1093/europace/euq503, indexed in Pubmed: 21242154

33. Rothman SA, Laughlin JC, Seltzer J, et al. The diagnosis of cardiac arrhythmias: a prospective multi-center randomized study comparing mobile cardiac outpatient telemetry versus standard loop event monitoring. J Cardiovasc Electrophysiol. 2007; 18(3): 241-247, doi: 10.1111/j.1540-8167.2006.00729.x, indexed in Pubmed: 17318994

34. Woelfel AK, Simpson RJ, Gettes LS, et al. Exercise-induced distal atrioventricular block. J Am Coll Cardiol. 1983; 2(3): 578-581, doi: 10.1016/ /s0735-1097(83)80288-5, indexed in Pubmed: 6875122.

35. Byrne JM, Marais HJ, Cheek GA. Exercise-induced complete heart block in a patient with chronic bifascicular block. J Electrocardiol. 1994; 27(4): 339-342, doi: 10.1016/s0022-0736(05)80273-0, indexed in Pubmed: 7815013

36. Aste M, Oddone D, Donateo P, et al. Syncope in patients paced for atrioventricular block. Europace. 2016; 18(11): 1735-1739, doi: 10.1093/europace/euv425, indexed in Pubmed: 26851815.

37. Sumiyoshi M, Nakata Y, Yasuda M, et al. Clinical and electrophysiologic features of exercise-induced atrioventricular block. Am Heart J. 1996; 132(6): 1277-1281, doi: 10.1016/s0002-8703(96)90476-7, indexed in Pubmed: 8969584

38. Wissocq L, Ennezat PV, Mouquet F. Exercise-induced high-degree atrioventricular block. Arch Cardiovasc Dis. 2009; 102(10): 733-735, doi: 10.1016/j.acvd.2009.06.003, indexed in Pubmed: 19913775.

39. McAnulty JH, Rahimtoola SH, Murphy E, et al. Natural history of high-risk bundle-branch block. N Engl J Med. 1982; 307(3): 137-143, doi: 10.1056/nejm198207153070301, indexed in Pubmed: 7088050.

40. Moya A, García-Civera R, Croci F, et al. Bradycardia detection in Bundle Branch Block (B4) study. Diagnosis, management, and outcomes of patients with syncope and bundle branch block. Eur Heart J. 2011; 32(12): 1535-1541, doi: 10.1093/eurheartj/ehr071, indexed in Pubmed: 21444367. 
41. Kalscheur MM, Donateo P, Wenzke KE, et al. Long-term outcome of patients with bifascicular block and unexplained syncope following cardiac pacing. Pacing Clin Electrophysiol. 2016; 39(10): 1126-1131, doi: 10.1111/pace.12946, indexed in Pubmed: 27565449.

42. Krahn AD, Klein GJ, Yee R, et al. Use of an extended monitoring strategy in patients with problematic syncope. Reveal Investigators. Circulation. 1999; 99(3): 406-410, doi: 10.1161/01.cir.99.3.406, indexed in Pubmed: 9918528.

43. Olshansky B, Hahn EA, Hartz VL, et al. Clinical significance of syncope in the electrophysiologic study versus electrocardiographic monitoring (ESVEM) trial. The ESVEM Investigators. Am Heart J. 1999; 137(5): 878-886, doi: 10.1016/s0002-8703(99)70412-6, indexed in Pubmed: 10220637.

44. Moya A, García-Civera R, Croci F, et al. Bradycardia detection in Bundle Branch Block (B4) study. Diagnosis, management, and outcomes of patients with syncope and bundle branch block. Eur Heart J. 2011; 32(12): 1535-1541, doi: 10.1093/eurheartj/ehr071, indexed in Pubmed: 21444367.

45. Gronda M, Magnani A, Occhetta E, et al. Electrophysiological study of atrio-ventricular block and ventricular conduction defects. Prognostic and therapeutical implications. G Ital Cardiol. 1984; 14(10): 768-773, indexed in Pubmed: 6519386.

46. Bergfeldt L, Edvardsson N, Rosenqvist M, et al. Atrioventricular block progression in patients with bifascicular block assessed by repeated electrocardiography and a bradycardia-detecting pacemaker. Am J Cardiol. 1994; 74(11): 1129-1132, doi: 10.1016/0002-9149(94)904650 , indexed in Pubmed: 7977072

47. Kaul U, DEV V, NARULA J, et al. Evaluation of patients with bundle branch block and "unexplained" syncope: a study based on comprehensive electrophysiologic testing and ajmaline stress. Pacing Clin Electrophysiol. 1988; 11(3): 289-297, doi: 10.1111/j.1540-8159.1988. tb05006.x, indexed in Pubmed: 2452415.

48. Kalscheur MM, Donateo P, Wenzke KE, et al. Long-term outcome of patients with bifascicular block and unexplained syncope following cardiac pacing. Pacing Clin Electrophysiol. 2016; 39(10): 1126-1131, doi: 10.1111/pace.12946, indexed in Pubmed: 27565449.

49. Scheinman MM, Peters RW, Suavé MJ, et al. Value of the H-Q interval in patients with bundle branch block and the role of prophylactic permanent pacing. Am J Cardiol. 1982; 50(6): 1316-1322, doi: 10.1016/0002-9149(82)90469-6, indexed in Pubmed: 7148708.

50. Dhingra RC. Sinus node dysfunction. Pacing Clin Electrophysiol. 1983; 6(5 Pt 2): 1062-1069, doi: 10.1111/j.1540-8159.1983.tb04445.x, indexed in Pubmed: 6195627.

51. Gann D, Tolentino A, Samet P. Electrophysiologic evaluation of elderly patients with sinus bradycardia: a long-term follow-up study. Ann Intern Med. 1979; 90(1): 24-29, doi: 10.7326/0003-4819-90-1-24, indexed in Pubmed: 420459.

52. Menozzi C, Brignole M, Alboni P, et al. The natural course of untreated sick sinus syndrome and identification of the variables predictive of unfavorable outcome. Am J Cardiol. 1998; 82(10): 1205-1209, doi: 10.1016/s0002-9149(98)00605-5, indexed in Pubmed: 9832095.

53. Priori SG, Blomström-Lundqvist C, Mazzanti A, et al. 2015 ESC Guidelines for the management of patients with ventricular arrhythmias and the prevention of sudden cardiac death: the Task Force for the Management of Patients with Ventricular Arrhythmias and the Prevention of Sudden Cardiac Death of the European Society of Cardiology (ESC). Endorsed by: Association for European Paediatric and Congenital Cardiology (AEPC). Eur Heart J. 2015; 36(41): 2793-2867, doi: 10.1093/ /eurheartj/ehv316, indexed in Pubmed: 26320108.

54. Blomström-Lundqvist C, Scheinman MM, Aliot EM, et al. American College of Cardiology, American Heart Association Task Force on Practice Guidelines, European Society of Cardiology Committee for Practice Guidelines. Writing Committee to Develop Guidelines for the Management of Patients With Supraventricular Arrhythmias. ACC/AHA/ESC guidelines for the management of patients with su- praventricular arrhythmias - executive summary: a report of the American College of Cardiology/American Heart Association Task Force on Practice Guidelines and the European Society of Cardiology Committee for Practice Guidelines (Writing Committee to Develop Guidelines for the Management of Patients With Supraventricular Arrhythmias). Circulation. 2003; 108(15): 1871-1909, doi: 10.1161/01. CIR.0000091380.04100.84, indexed in Pubmed: 14557344

55. Brignole M, Auricchio A, de Lange FJ, et al. Grupa Robocza Europejskiego Towarzystwa Kardiologicznego (ESC) do spraw stymulacji serca i terapii resynchronizującej we współpracy z European Heart Rhythm Association (EHRA). Wytyczne ESC dotyczące stymulacji serca i terapii resynchronizującej w 2013 roku. Kardiol Pol. 2013; 71(Suppl V): 133-192, doi: 10.5603/kp.2013.0182.

56. Alboni P, Menozzi C, Brignole M, et al. Effects of permanent pacemaker and oral theophylline in sick sinus syndrome the THEOPACE study: a randomized controlled trial. Circulation. 1997; 96(1): 260-266, doi: 10.1161/01.cir.96.1.260, indexed in Pubmed: 9236443.

57. Breivik K, Ohm OJ, Segadal L. Sick sinus syndrome treated with permanent pacemaker in 109 patients. A follow-up study. Acta Med Scand. 1979; 206(3): 153-159, doi: 10.1111/j.0954-6820.1979. tb13486.x, indexed in Pubmed: 495220.

58. Härtel G, Talvensaari T. Treatment of sinoatrial syndrome with permanent cardiac pacing in 90 patients. Acta Med Scand. 1975; 198(5): 341-347, doi: 10.1111/j.0954-6820.1975.tb19555.x, indexed in Pubmed: 1199808

59. Rasmussen K. Chronic sinus node disease: natural course and indications for pacing. Eur Heart J. 1981; 2(6): 455-459, doi: 10.1093/ /oxfordjournals.eurheartj.a061236, indexed in Pubmed: 7338247.

60. Sasaki Y, Shimotori M, Akahane K, et al. Long-term follow-up of patients with sick sinus syndrome: a comparison of clinical aspects among unpaced, ventricular inhibited paced, and physiologically paced groups. Pacing Clin Electrophysiol. 1988; 11 (11 Pt 1): 1575-1583, doi: 10.1111/j.1540-8159.1988.tb06277.x, indexed in Pubmed: 2462243.

61. Brignole M, Arabia F, Ammirati F, et al. Syncope Unit Project 2 (SUP 2) investigators. Standardized algorithm for cardiac pacing in older patients affected by severe unpredictable reflex syncope: 3-year insights from the Syncope Unit Project 2 (SUP 2) study. Europace. 2016; 18(9): 1427-1433, doi: 10.1093/europace/euv343, indexed in Pubmed: 26612880.

62. Brignole M, Menozzi C. The natural history of carotid sinus syncope and the effect of cardiac pacing. Europace. 2011; 13(4): 462-464, doi: 10.1093/europace/euq516, indexed in Pubmed: 21447520.

63. Gaggioli G, Brignole M, Menozzi C, et al. A positive response to head-up tilt testing predicts syncopal recurrence in carotid sinus syndrome patients with permanent pacemakers. Am J Cardiol. 1995; 76(10): 720-722, doi: 10.1016/s0002-9149(99)80207-0, indexed in Pubmed: 7572635

64. Deharo JC, Guieu R, Mechulan A, et al. Syncope without prodromes in patients with normal heart and normal electrocardiogram: a distinct entity. J Am Coll Cardiol. 2013; 62(12): 1075-1080, doi: 10.1016/j. jacc.2013.05.060, indexed in Pubmed: 23810895.

65. Brignole M, Deharo JC, De Roy L, et al. Syncope due to idiopathic paroxysmal atrioventricular block: long-term follow-up of a distinct form of atrioventricular block. J Am Coll Cardiol. 2011; 58(2): 167-173, doi: 10.1016/j.jacc.2010.12.045, indexed in Pubmed: 21570228.

66. Brignole M, Guieu R, Tomaino M, et al. Mechanism of syncope without prodromes with normal heart and normal electrocardiogram. Heart Rhythm. 2017; 14(2): 234-239, doi: 10.1016/j.hrthm.2016.08.046, indexed in Pubmed: 27639455.

67. Brignole M, Menozzi C, Moya A, et al. International Study on Syncope of Uncertain Etiology 3 (ISSUE-3) Investigators. Pacemaker therapy in patients with neurally mediated syncope and documented asystole: Third International Study on Syncope of Uncertain Etiology (ISSUE-3): a randomized trial. Circulation. 2012; 125(21): 
2566-2571, doi: 10.1161/CIRCULATIONAHA.111.082313, indexed in Pubmed: 22565936.

68. Puggioni E, Guiducci V, Brignole M, et al. Results and complications of the carotid sinus massage performed according to the "method of symptoms". Am J Cardiol. 2002; 89(5): 599-601, doi: 10.1016/ /s0002-9149(01)02303-7, indexed in Pubmed: 11867049.

69. Sutton R, Brignole M, Menozzi C, et al. Dual-chamber pacing in the treatment of neurally mediated tilt-positive cardioinhibitory syncope : pacemaker versus no therapy: a multicenter randomized study. The Vasovagal Syncope International Study (VASIS) Investigators. Circulation. 2000; 102(3): 294-299, doi: 10.1161/01.cir.102.3.294, indexed in Pubmed: 10899092.

70. Ammirati F, Colivicchi F, Santini M, et al. Syncope Diagnosis and Treatment Study Investigators. Permanent cardiac pacing versus medical treatment for the prevention of recurrent vasovagal syncope: a multicenter, randomized, controlled trial. Circulation. 2001; 104(1): 52-57, doi: 10.1161/hc2601.091708, indexed in Pubmed: 11435337.

71. Barón-Esquivias G, Moya-Mitjans A, Martinez-Alday J, et al. Dual-Chamber Pacing With Closed Loop Stimulation in Recurrent Reflex Vasovagal Syncope: The SPAIN Study. J Am Coll Cardiol. 2017; 70(14): 1720-1728, doi: 10.1016/j.jacc.2017.08.026, indexed in Pubmed: 28958328.

72. Flammang D, Church TR, De Roy L, et al. ATP Multicenter Study. Treatment of unexplained syncope: a multicenter, randomized trial of cardiac pacing guided by adenosine 5'-triphosphate testing. Circulation. 2012; 125(1): 31-36, doi: 10.1161/CIRCULATIONAHA.111.022855, indexed in Pubmed: 22086879

73. Brignole M, Guieu R, Tomaino M, et al. Mechanism of syncope without prodromes with normal heart and normal electrocardiogram. Heart Rhythm. 2017; 14(2): 234-239, doi: 10.1016/j.hrthm.2016.08.046, indexed in Pubmed: 27639455.

74. Connolly SJ, Sheldon R, Thorpe KE, et al. VPS II Investigators. Pacemaker therapy for prevention of syncope in patients with recurrent severe vasovagal syncope: Second Vasovagal Pacemaker Study (VPS II): a randomized trial. JAMA. 2003; 289(17): 2224-2229, doi: 10.1001/ /jama.289.17.2224, indexed in Pubmed: 12734133.

75. Raviele A, Giada F, Menozzi C, et al. Vasovagal Syncope and Pacing Trial Investigators. A randomized, double-blind, placebo-controlled study of permanent cardiac pacing for the treatment of recurrent tilt-induced vasovagal syncope. The vasovagal syncope and pacing trial (SYNPACE). Eur Heart J. 2004; 25(19): 1741-1748, doi: 10.1016/j. ehj.2004.06.031, indexed in Pubmed: 15451153.

76. Behar S, Zissman E, Zion M, et al. Prognostic significance of second-degree atrioventricular block in inferior wall acute myocardial infarction. SPRINT Study Group. Am J Cardiol. 1993; 72(11): 831-834, doi: 10.1016/0002-9149(93)91075-s, indexed in Pubmed: 8213521.

77. Col JJ, Weinberg SL. The incidence and mortality of intraventricular conduction defects in acute myocardial infarction. Am J Cardiol.
1972; 29(3): 344-350, doi: 10.1016/0002-9149(72)90529-2, indexed in Pubmed: 5060806.

78. Ginks WR, Sutton R, Oh W, et al. Long-term prognosis after acute anterior infarction with atrioventricular block. Br Heart J. 1977; 39(2): 186-189, doi: 10.1136/hrt.39.2.186, indexed in Pubmed: 836733.

79. Jim MH, Chan AOO, Tse HF, et al. Clinical and angiographic findings of complete atrioventricular block in acute inferior myocardial infarction. Ann Acad Med Singapore. 2010; 39(3): 185-190, indexed in Pubmed: 20372753

80. Gang UJ, Hvelplund A, Pedersen S, et al. High-degree atrioventricular block complicating ST-segment elevation myocardial infarction in the era of primary percutaneous coronary intervention. Europace. 2012; 14(11): 1639-1645, doi: 10.1093/europace/eus161, indexed in Pubmed: 22645234.

81. Chang SuM, Nagueh SF, Spencer WH, et al. Complete heart block: determinants and clinical impact in patients with hypertrophic obstructive cardiomyopathy undergoing nonsurgical septal reduction therapy. J Am Coll Cardiol. 2003; 42(2): 296-300, doi: 10.1016/s07351097(03)00623-5, indexed in Pubmed: 12875767.

82. Topilski I, Sherez J, Keren G, et al. Long-term effects of dual-chamber pacing with periodic echocardiographic evaluation of optimal atrioventricular delay in patients with hypertrophic cardiomyopathy $>50$ years of age. Am J Cardiol. 2006; 97(12): 1769-1775, doi: 10.1016/j.amjcard.2006.01.040, indexed in Pubmed: 16765132

83. Kappenberger LJ, Linde C, Jeanrenaud X, et al. Pacing in hypertrophic obstructive cardiomyopathy. A randomized crossover study. PIC Study Group. Eur Heart J. 1997; 18(8): 1249-1256, doi: 10.1093/oxfordjournals.eurheartj.a015435, indexed in Pubmed: 9458416

84. Maron BJ, Nishimura RA, McKenna WJ, et al. Assessment of permanent dual-chamber pacing as a treatment for drug-refractory symptomatic patients with obstructive hypertrophic cardiomyopathy. A randomized, double-blind, crossover study (M-PATHY). Circulation. 1999; 99(22): 2927-2933, doi: 10.1161/01.cir.99.22.2927, indexed in Pubmed: 10359738.

85. Nishimura RA, Trusty JM, Hayes DL, et al. Dual-chamber pacing for hypertrophic cardiomyopathy: a randomized, double-blind, crossover trial. J Am Coll Cardiol. 1997; 29(2): 435-441, doi: 10.1016/s07351097(96)00473-1, indexed in Pubmed: 9015001.

86. Galve E, Sambola A, Saldaña G, et al. Late benefits of dual-chamber pacing in obstructive hypertrophic cardiomyopathy: a 10-year follow-up study. Heart. 2010; 96(5): 352-356, doi: 10.1136/hrt.2008.158915, indexed in Pubmed: 19482844.

87. Megevand A, Ingles J, Richmond DR, et al. Long-term follow-up of patients with obstructive hypertrophic cardiomyopathy treated with dual-chamber pacing. Am J Cardiol. 2005; 95(8): 991-993, doi: 10.1016/j. amjcard.2004.12.045, indexed in Pubmed: 15820173. 